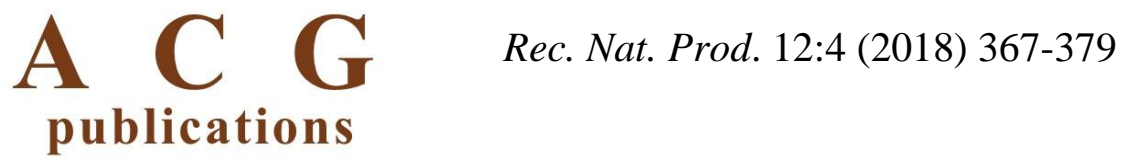

\title{
Phytochemical and Biological Evaluation of Ultrasound-Assisted Spray Dried Lonicera etrusca for Potential Management of Diabetes
}

\author{
Karim M. Raafat ${ }^{\odot 1, *}$ and Wael Samy ${ }^{\odot 2}$ \\ ${ }^{1}$ Department of Pharmaceutical Sciences, Faculty of Pharmacy, Beirut Arab University, \\ 115020 Beirut, Lebanon \\ ${ }^{2}$ Department of Industrial Pharmacy, Faculty of Pharmacy, Alexandria University, \\ 21521 Alexandria, Egypt
}

(Received October 19, 2017; Revised November 26, 2017; Accepted December 10, 2017)

\begin{abstract}
Honeysuckle or Lonicera etrusca is one of the important medicinal-plants that is traditionally-used as a potential antioxidant. The aim of this work was to make a phytochemical-evaluation of Lonicera etrusca ultrasound-assisted spray-dried extract versus conventional-method utilizing RP-HPLC aided-method in the potential management of diabetes. Ultrasound-assisted spray-drying (US-SD) is a new productive-technique aiming at increasing the efficiency and extract-yield in addition to short time of exposure to elevated temperature thus improving product stability. A bio-guided study utilizing RP-HPLC, ${ }^{1} \mathrm{H}$ and ${ }^{13} \mathrm{C}$ NMR methods indicated that the most active antidiabetic-compound was isochlorogenic acid (ICA). Diabetes measurement utilizing glucometers and HbAlc methods was applied. Serum-insulin levels and serum-catalase (CAT) was also monitored. The US-SD preserved time by 4 folds and with higher yield (ca. 20\%) than the conventional method. The US-SD also had higher quality in US-SD honeysuckle (HS-sd) constituents than the conventional method as supported by RP-HPLC analysis. Rotary evaporated honeysuckle (HS-r) major peaks identified were; chlorogenic acid $(38.6 \%)$, caffeic acid (5.8\%), isochlorogenic acid $(36.1 \%)$, luteolin-7-O-glucoside $(3.3 \%)$, and quercetin (3.0\%). HS-sd major peaks identified were; chlorogenic acid (40.5\%), caffeic acid (6.4\%), isochlorogenic acid $(43.3 \%)$, luteolin-7-O-glucoside $(3.5 \%)$, and quercetin $(3.2 \%)$. HS-sd had significant ( $<<0.05, n=7 / g r o u p)$ antidiabetic-activity more than HS-r. HS-sd had more-significant dose-dependent increase in serum-insulin, CATlevels and body-weights more prominent than HS-r. Compared to conventional-methods, US-SD has shown to be time-conserving, efficient, and active-ingredients preserving method. The antidiabetic-potentials of HS-sd and ICA were probably mediated via the significant insulin-secretagogue effect and the attenuation glucose-provoked oxidative-stress.
\end{abstract}

Keywords: Lonicera etrusca; isochlorogenic acid; ultrasound-assisted spray drying; RP-HPLC; diabetes. (C) 2018 ACG Publications. All rights reserved.

\section{Introduction}

Medicinal plants contain different phytochemicals which play an essential role in prevention of many disorders by boosting up various organ functions of the human body, reducing the oxidative stress and enhancing vital tissues regeneration [1]. One of the important medicinal plants is Honeysuckle. Honeysuckle or Lonicera etrusca [Caprifoliaceae] (L. etrusca) is a Mediterranean climbing shrub

\footnotetext{
* Corresponding author: E-Mail: k.raafat@bau.edu.lb
} 
famous for its colorful flowers. The blooming period starts in May and finishes in June. It is traditionally used in Asia as antioxidant, diuretic and anti-fatigue [2, 3].

One of the autoimmune disorders that might be managed by medicinal plants and its isolated phytochemicals is diabetes (DM). DM is a major health disorder and is a leading reason of death worldwide. DM is marked by the increased oxidative stress and very low insulin secretion due to degeneration of the pancreatic beta-cells [4].

For manufacturing purposes, spray drying is one of the most convenient methods for drying natural medicine, having several pros over other conventional drying methods. Spray drying might help in solving many problems that decrease natural medicine efficacy like stability and quality of active constituents [5].

To date, there are few reports about L. etrusca and its phytochemical active ingredients. Moreover, L. etrusca has not been reported before to manage DM. Nevertheless, its promising antioxidant potentials have motivated the trials on management of DM. Thus, the aim of the current work is to phytochemically investigate the ultrasound-assisted spray dried L. etrusca, its potential antidiabetic activity, the possible active constituents and the underling mechanism of action.

\section{Materials and Methods}

\subsection{Plant Material}

Lonicera etrusca flowers was collected in May 2014 from Beirut, Lebanon (Latitude: 33.90131 North and Longitude: 35.48034 East) and was authenticated by a reference-sample, and a sample was kept in the faculty herbarium utilizing a voucher sample number (P14-48).

\subsection{Ultrasound-assisted Spray Drying versus Conventional Rotary-evaporation}

The fresh L. etrusca flowers were divided into 2 equal halves. The first half was vortexed conventionally with Stuart vortex (China) with double distilled water for $12 \mathrm{~h}$ and the aqueous extract dried under vacuum utilizing Buchi rotavapor (Germany) at $40^{\circ} \mathrm{C}$ till complete dryness producing the Honeysuckle rotavapor extract (HS-r). The second half was sonicated for $3 \mathrm{~h}$ with double distilled water in Altrasonic ultrasonic atomizer (China) with a working frequency of $40 \mathrm{kHz}$ and a cylindrical flange vibrating symmetrically, to avoid fluid gliding. The atomized aqueous extract was then fed into LabPlant Mini-Spray dryer SD-06AG (Lab-Plant, UK). Where, the inlet-temperature was adjusted at $165^{\circ} \mathrm{C}$ and the feed rate was adjusted keeping the outlet-temperature at $75-80^{\circ} \mathrm{C}$ [6]. The spray dried extract (HS-sd) was collected and kept in a desiccator till further testing.

\subsection{L. etrusca Extracts and RP-HPLC Standardization}

HS-r and HS-sd were standardized separately utilizing an RP-HPLC method. The HPLC system utilized was assembled of an Agilent-Technologies HPLC model (1200 series) supplied with quaternary-pump module, thermostatted column-compartment, vacuum degasser, and UV-detector system. Data acquisition was carried out by Agilent ChemStation-software. RP-analysis was carried out with an Agilent C-18 column $(4.6 \mathrm{~mm} \times 250 \mathrm{~mm}, 5 \mu \mathrm{m}$ particle size $)$ at $40{ }^{\circ} \mathrm{C}$. The mobile phase consisted of isocratic $\mathrm{MeOH} / \mathrm{Phosphate}$ buffer $\mathrm{pH}=2.1$ (43:57). Both phases were degassed using Grant sonication-bath for $25 \mathrm{~min}$. The injection-volume was $50 \mu \mathrm{L}$ and the flow-rate was kept at $1.0 \mathrm{ml} / \mathrm{min}$. The standardization of HS-r or HS-sd was carried out at $254 \mathrm{~nm}$ [7].

\subsection{Bio-guided Fractionation, Isolation and NMR Identification of Active Constituent}

The bio-guided fractionation was performed using RP-silica gel packed in a glass-column $(50 \mathrm{~mm} \times 400 \mathrm{~mm})$. The volume of HS-sd was adjusted according to the volume of column packing and was left to equilibrate. The column was eluted with one bed volume (BV) of double-distilled water, followed 5BV EtOH (30\%) and finally 2BV EtOH (100\%). During the whole fractionation process aliquots was collected every 2 min, concentrated and monitored utilizing TLC and RP-HPLC. Similar 
aliquots was combined, concentrated and tested for acute hypoglycemic potentials. The most active aliquot was identified utilizing Bruker ${ }^{1} \mathrm{H}$ and ${ }^{13} \mathrm{C}$ NMR (300 MHz) (Germany). For NMR analysis, 100 $\mu \mathrm{L}$ of the active aliquot was mixed three times with $100 \mu \mathrm{L} 100 \% \mathrm{D} 2 \mathrm{O}(0.9 \%$, w/v). Then ca. $150 \mu \mathrm{L}$ of the supernatant was transferred into NMR (3 mm) tubes.

\subsection{Animals and Diabetes Induction}

\subsubsection{Ethics Statement}

The use and care of the experimental protocol and animals was in compliance with the Guidelines for the Use and Care of Experimental Animals of BAU University, and was approved by BAU Institutional Review Board.

\subsubsection{Diabetes Induction}

Male mice, weighing 22-28 g, were obtained from the faculty animal-house (Lebanon). Mice were housed in a room which is temperature-controlled $\left(20 \pm 2{ }^{\circ} \mathrm{C} ; 12 \mathrm{~h} \mathrm{light/dark} \mathrm{cycle)} \mathrm{with} \mathrm{free}\right.$ access to food and water. After acclimatization for a week, DM was induced with three intraperitoneal injection of alloxan each other day at a total dose of $180 \mathrm{mg} / \mathrm{kg}$. After three days, blood glucose levels (BGL) were monitored and the mice with a BGL more than $200 \mathrm{mg} / \mathrm{dL}$ was classified as diabetic [8].

\subsubsection{Experimental Design and Measurement of Blood Glucose Levels, Body Weights and Catalase Levels}

The experimental design was summarized in table 1 . All treatments were given orally via oral gavages. Blood was collected by tail-vein puncture and BGL was measured acutely and subchronically by Sigma glucometers (Germany) and for longer times by Analyticon HbA1c micro-columns (Germany). Acutely, the BGL was measured pre-treatment and 0.5, 2 and $6 \mathrm{~h}$ post-treatment. Subchronically, the BGL was monitored at pre-treatment (day 0 ) and days $1,3,5$ and 8 post-treatment. For longer times, the HbA1c was measured at day 0 , and at day 28 post-treatment.

\subsubsection{Serum Insulin Levels}

The serum insulin levels were monitored for longer time at day 0 , and at day 28 post HS-r (10, 25 and $50 \mathrm{mg} / \mathrm{kg}$ ), HS-sd $(10,25$ and $50 \mathrm{mg} / \mathrm{kg})$, and ICA $(5,10$ and $20 \mathrm{mg} / \mathrm{kg}$ ) treatment using an RPHPLC method reported-before [9]. Briefly, HPLC system (Agilent, Japan) equipped by RP-C18 column (Merck, Germany), and the mobile-phase consisted of TFA $(0.1 \%)$ in HPLC double-distilled water (solvent-A) and ACN (solvent-B) and the column temperature was adjusted to $40^{\circ} \mathrm{C}$ at $1 \mathrm{ml} / \mathrm{min}$ flowrate. At $214 \mathrm{~nm}$, the gradient-elution conditions utilized were 0-5 min 70\% A, 5-15 $\min 60 \% \mathrm{~A}$ [10].

\subsubsection{Body Weight and Catalase Levels}

During the subchronic monitoring of BGL, animals body weight (BW) and serum catalase levels (CAT) were recorded. The body weights and CAT levels were measured at pre-treatment (day 0 ) and days 1, 3, 5 and 8 post-treatment in grams and kU/I, respectively [11].

\subsection{Statistical Analysis}

All results were measured as mean \pm S.E.M. The mean differences were compared by ANOVA. The Scheffe and Duncan methods were utilized to carry out post hoc analysis utilizing "OriginPro" statistics-program. The $p$-value $\leq 0.05$ was appointed as statistically-significant result. 
Table 1. Protocol of experimental design

\begin{tabular}{cccl}
\hline Groups & $\mathbf{n}$ & $\begin{array}{c}\text { Tested } \\
\text { Substance(s) }\end{array}$ & Description \\
\hline I & 7 & Control & Normal mice: Vehicle [sterile cold saline (0.9\%)], IP \\
II & 7 & Diabetic Control & Diabetic mice: Vehicle, IP \\
III & 7 & GB & Diabetic mice: GB $5 \mathrm{mg} / \mathrm{kg}$, IP \\
IV & 7 & HS-r & Diabetic mice: HS-r 10 mg/kg, IP \\
V & 7 & HS-r & Diabetic mice: HS-r $25 \mathrm{mg} / \mathrm{kg}$, IP \\
VI & 7 & HS-r & Diabetic mice: HS-r $50 \mathrm{mg} / \mathrm{kg}$, IP \\
VII & 7 & HS-sd & Diabetic mice: HS-sd $10 \mathrm{mg} / \mathrm{kg}$, IP \\
VIII & 7 & HS-sd & Diabetic mice: HS-sd $25 \mathrm{mg} / \mathrm{kg}$, IP \\
IX & 7 & HS-sd & Diabetic mice: HS-sd $50 \mathrm{mg} / \mathrm{kg}$, IP \\
X & 7 & ICA & Diabetic mice: ICA $5 \mathrm{mg} / \mathrm{kg}$, IP \\
XI & 7 & ICA & Diabetic mice: ICA $10 \mathrm{mg} / \mathrm{kg}$, IP \\
XII & 7 & ICA & Diabetic mice: ICA $20 \mathrm{mg} / \mathrm{kg}$, IP
\end{tabular}

Acute $(0,0.5,2$ and $6 \mathrm{hrs})$ and subchronic (1,3,5,8 days) effect of rotary evaporated Honeysuckle aqueous extract (HS-r), ultrasound-assisted spray dried Honeysuckle aqueous extract (HS-sd) and isolated isochlorogenic acid (ICA) from HS-sd on blood glucose, body weights and CAT serum levels.

\section{Results and Discussion}

\subsection{L. etrusca Extract RP-HPLC Standardization}

The rotary evaporated extract (HS-r) and the spray dried one (HS-sd) were standardized by means of RP-HPLC analysis and the use of steeping of standard calibration curves method. HS-r major peaks identified were (I) Chlorogenic acid (38.6\%), (II) Caffeic acid (5.8\%), (III) Isochlorogenic acid (36.1\%), (IV) luteolin-7-O-glucoside (3.3\%), and (V) quercetin (3.0\%). On the other hand, HS-sd r major peaks identified were (I) Chlorogenic acid (40.5\%), (II) Caffeic acid (6.4\%), (III) Isochlorogenic acid (43.3\%), (IV) luteolin-7-O-glucoside (3.5\%), and (V) quercetin (3.2\%) (Figure 1).

\subsection{Bio-guided Separation, Isolation and ${ }^{1} \mathrm{H}$ and ${ }^{13} \mathrm{C}$ NMR Data of Active Constituent}

The most active fraction isolated by RP-column chromatography from HS-sd was identified by ${ }^{1} \mathrm{H}$ and ${ }^{13} \mathrm{C}$ NMR to be isochlorogenic acid (ICA) (Table 2 and Figure 2). Various doses of HS-r $(10,25$ and $50 \mathrm{mg} / \mathrm{kg}$ ), HS-sd $(10,25$ and $50 \mathrm{mg} / \mathrm{kg})$, and ICA $(5,10$ and $20 \mathrm{mg} / \mathrm{kg})$ were used in the antidiabetic studies. The choice of various doses was according to the percentage of ICA in HS, and dose-adjustment method via an acute pilot study prior to beginning of the experimentation.

\subsection{Ultrasound-assisted Spray Drying versus Conventional Rotary-evaporation}

Rotary evaporation is one of the most common drying procedures conventionally used. In the current work, the conventional rotary evaporation drying method yield was compared to the ultrasoundassisted spray drying method. The main drawback of the rotary evaporation is the longer drying time and the lower yield when compared to the ultrasound-assisted spray drying method. The conditions of the various methods and their corresponding results were summed up in Table 3. Concerning the drying time, spray drying was found to be faster by 4 folds than that of conventional rotator evaporation method (Table 3).

In terms of yield, the comparatively marked results were obtained by spray drying, which has given higher yield by ca. $20.0 \%$, when compared to the rotary evaporation method (Table 3 ). The ultrasound-assisted spray drying method has shown to save considerable time and to have superior yield over the rotary evaporation method. 


\subsection{Measurement of Blood Glucose and HbAlc Levels}

Acutely, various doses of HS-r $(10,25$ and $50 \mathrm{mg} / \mathrm{kg})$ have decreased the BGL at $6 \mathrm{~h}$ posttreatment by $27.3,29.0$ and $30.7 \%$, respectively, in correlation with vehicle treated diabetic animal group (DIA CTRL) (Figure 3A). Moreover, the same doses of the spray dried HS-sd (10, 25 and 50 $\mathrm{mg} / \mathrm{kg}$ ) have potentially decreased the BGL after $6 \mathrm{~h}$ post-treatment by $42.7,44.8$ and $50.0 \%$, respectively, in correlation with DIA CTRL (Figure 3B). The strongest effect was obtained with the most active compound isolated from HS-sd, ICA $(5,10$ and $20 \mathrm{mg} / \mathrm{kg}$ ) showing $6 \mathrm{~h}$ post-treatment BGL reduction of $41.3,45.7$ and $52.7 \%$ (Figure 3C), respectively.

Subchronic activity of the prepared extracts were tested in correlation with vehicle treated diabetic animal group (DIA CTRL) where various doses of HS-r $(10,25$ and $50 \mathrm{mg} / \mathrm{kg}$ ) have decreased the BGL at 8 days post-treatment by $40.8,42.0$ and $43.5 \%$, respectively (Figure $4 \mathrm{~A}$ ). Moreover, the same doses of the spray dried HS-sd $(10,25$ and $50 \mathrm{mg} / \mathrm{kg}$ ) have potentially decreased the BGL after 8 days posttreatment by 50.6, 53.0 and 55.1\%, respectively, (Figure 4B). In case of the most active compound isolated from HS-sd, ICA $(5,10$ and $20 \mathrm{mg} / \mathrm{kg})$ the BGL after 8 days post-treatment was reduced by 43.2, 47.1 and 50.7\%; respectively (Figure 4C).
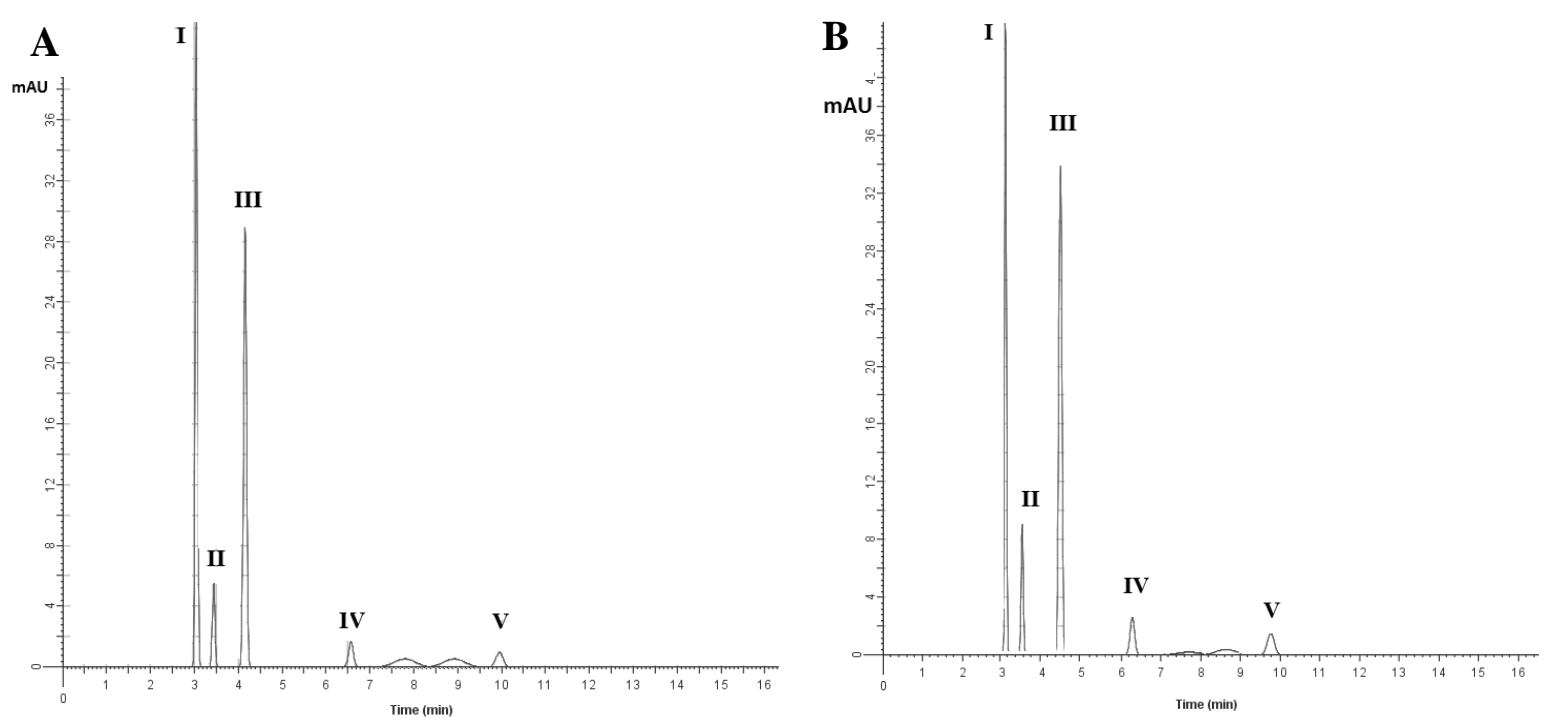

Figure 1. HPLC chromatograms for Lonicera etrusca: (A) HS-r major peaks identified were (I) Chlorogenic acid (38.6\%), (II) Caffeic acid (5.8\%), (III) Isochlorogenic acid (36.1\%), (IV) luteolin-7-Oglucoside $(3.3 \%)$, and (V) quercetin (3.0\%). (B) HS-sd $\mathrm{r}$ major peaks identified were (I) Chlorogenic acid $(40.5 \%)$, (II) Caffeic acid (6.4\%), (III) Isochlorogenic acid (43.3\%), (IV) luteolin-7-O-glucoside (3.5\%), and (V) quercetin (3.2\%). The mobile phase utilized was $\mathrm{MeOH} / \mathrm{Phosphate}$ buffer $\mathrm{pH}=2.1$ (43:57) at $254 \mathrm{~nm}$ and temperature $40^{\circ} \mathrm{C}$.

For longer periods, various doses of HS-r, HS-sd and the isolated ICA have shown significant decrease in $\mathrm{HbA1c}$ levels, 28 days post-administration, in correlation with vehicle treated diabetic mice (VEH) (Figure 5). The spray dried HS-sd had shown the most significant dose-dependent normalization of HbA1c levels. As HS-sd (10, 25 and $50 \mathrm{mg} / \mathrm{kg}$ ) have normalized the HbA1c level (VEH= $8.80 \pm$ $0.10 \%$ ) to $7.40 \pm 0.10,7.20 \pm 0.09$ and $7.00 \pm 0.09 \%$, respectively, after 28 days post-treatment. While those of HS-r $(10,25$ and $50 \mathrm{mg} / \mathrm{kg}$ ) have decreased the HbAlc level to $7.90 \pm 0.10,7.70 \pm 0.14$ and $7.50 \pm 0.02 \%$. Comparatively, the lowest decrease of control ( $\mathrm{n}=7 /$ group). CTRL $=$ normal non-diabetic control. * means significant $(p<0.05)$ compared to vehicle treated diabetic control (DIA-CTRL).

HbA1c levels have shown 28 days post-treatment by the isolated ICA which decreased the $\mathrm{HbA1c}$ levels to $8.00 \pm 0.09,7.80 \pm 0.08$ and $7.60 \pm 0.10 \%$, respectively (Figure 5). 


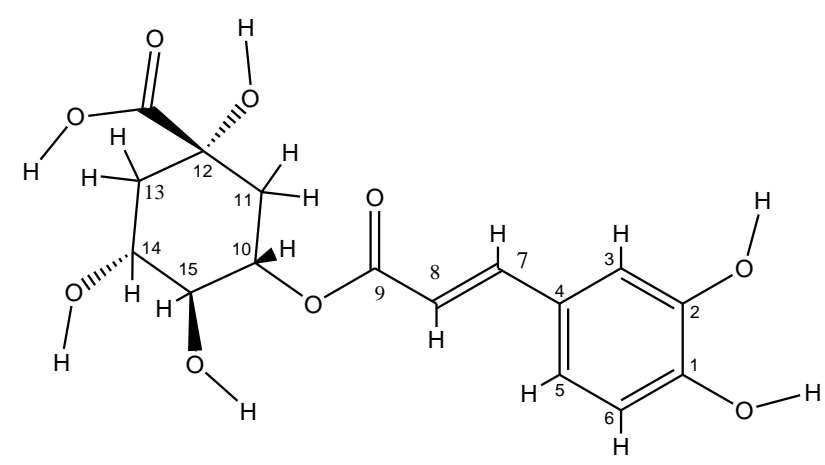

Figure 2. Structure of Isochlorogenic acid (ICA) isolated from Lonicera etrusca aqueous extract.

Table 2. ${ }^{1} \mathrm{H}$ and ${ }^{13} \mathrm{C}$ NMR spectroscopic data $(300 \mathrm{MHz})$ for isochlorogenic acid (ICA) isolated from ultrasound-assisted spray dried Lonicera etrusca aqueous extract.

\begin{tabular}{ccc}
\hline Position & $\boldsymbol{\delta}_{\mathbf{H}}$, multi. $(\boldsymbol{J}$ in Hz) & $\boldsymbol{\delta}_{\mathbf{C}}$ \\
\hline 1 & $4.09, \mathrm{t}(8.20)$ & 146.6 \\
2 & - & 146.4 \\
3 & $7.28, \mathrm{dd}(1.94,0.46)$ & 117.6 \\
4 & - & 127.2 \\
5 & $7.69, \mathrm{dd}(8.45,1.94)$ & 123.1 \\
6 & $6.77, \mathrm{dd}(8.45,0.46)$ & 116.2 \\
7 & $7.74, \mathrm{~d}(15.69)$ & 146.7 \\
8 & $6.50, \mathrm{~d}(15.69)$ & 115.9 \\
9 & - & 168.0 \\
10 & $5.04, \mathrm{q}(14.48,2.79)$ & 106.6 \\
$11 \alpha$ & $2.12, \mathrm{dd}(14.48,2.79)$ & 38.4 \\
$11 \beta$ & $2.32, \mathrm{dd}(14.25,2.79)$ & 71.9 \\
12 & $1.98, \mathrm{dd}(14.25,10.26)$ & 38.2 \\
$13 \alpha$ & $2.30, \mathrm{dd}(14.48,2.79)$ & 70.4 \\
$13 \beta$ & $3.38, \mathrm{dt}(10.26,2.79)$ & 73.5 \\
14 & $3.22, \mathrm{t}(2.79)$ &
\end{tabular}

Table 3. Comparison of the efficacy of rotary evaporated HS-r and the ultrasound-assisted spray dried HS-sd yields of Lonicera etrusca extract.

\begin{tabular}{ccccccc}
\hline Method & $\begin{array}{c}\text { Initial weight } \\
(\mathbf{g})\end{array}$ & $\begin{array}{c}\text { Solvent } \\
\text { volume } \\
(\mathbf{L})\end{array}$ & $\begin{array}{c}\text { Extraction } \\
\text { time } \\
(\mathbf{h r})\end{array}$ & $\begin{array}{c}\text { Drying } \\
\text { time } \\
(\mathbf{h r})\end{array}$ & $\begin{array}{c}\text { Rate of } \\
\text { drying } \\
(\mathbf{L} / \mathbf{h r})\end{array}$ & $\begin{array}{c}\text { Yield } \\
(\mathbf{g} / \mathbf{L})\end{array}$ \\
\hline HS-r & 1000 & 5 & 12 & 10 & 0.5 & 88.0 \\
HS-sd & 1000 & 5 & 3 & 2.5 & 2 & 110.0 \\
\hline
\end{tabular}


A

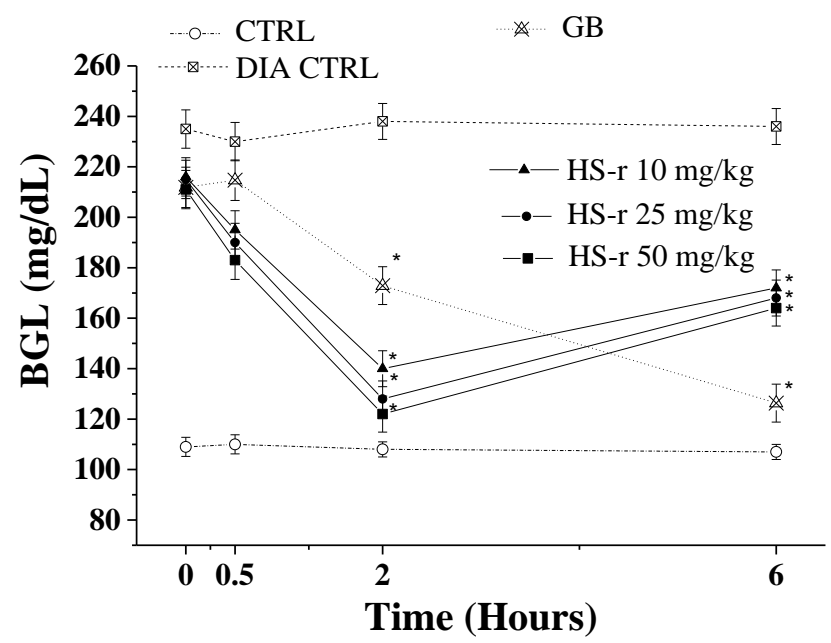

B

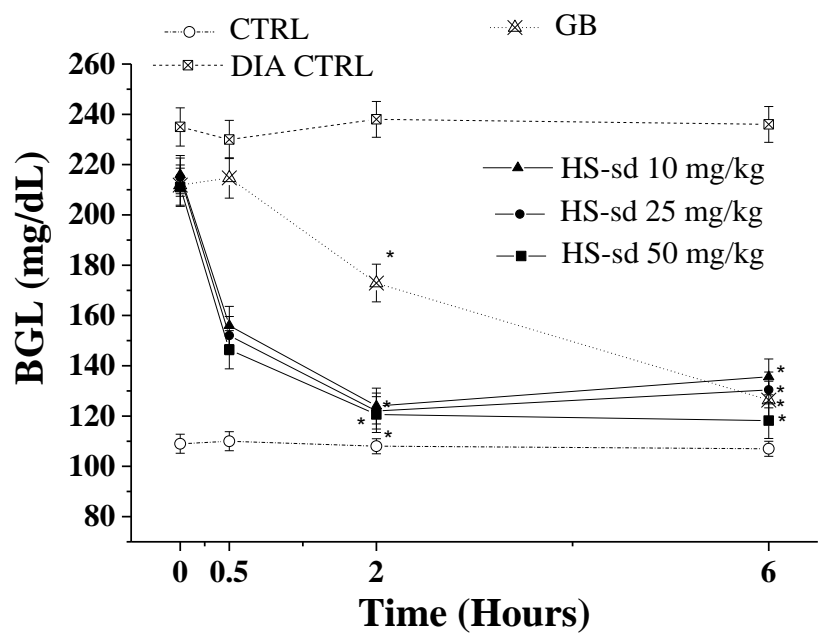

$\mathbf{C}$

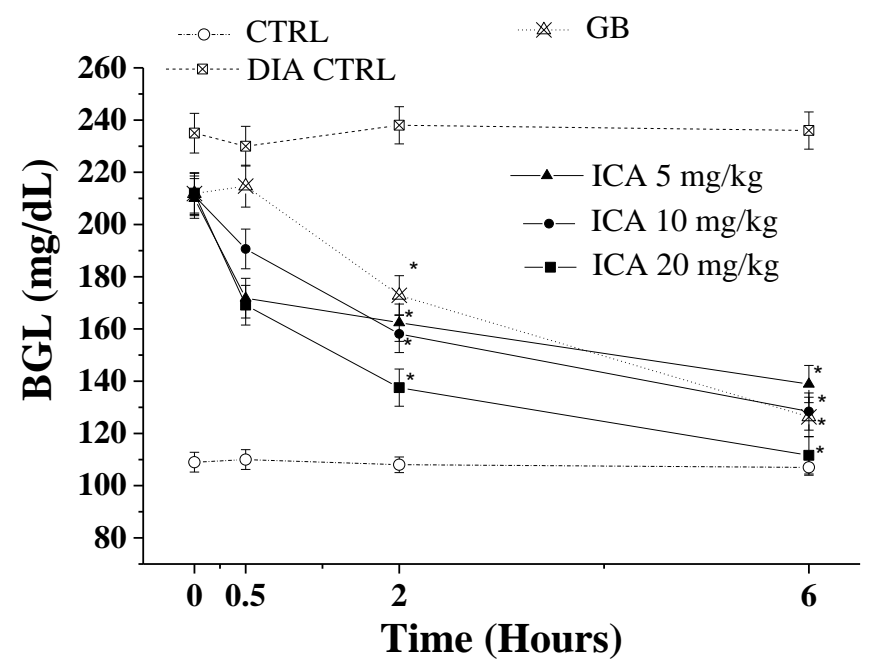

Figure 3. Acute hypoglycemic effect of (A) Rotary evaporated Honeysuckle aqueous extract (HS-r); (B) ultrasound-assisted spray dried Honeysuckle aqueous extract (HS-sd); and (C) the isolated isochlorogenic acid (ICA) from HS-sd on BGL of experimental diabetic mice utilizing glibenclamide (GB) as positive control ( $\mathrm{n}=7 /$ group). $\mathrm{CTRL}=$ normal non-diabetic control. $*$ means significant $(p<$ 0.05) compared to vehicle treated diabetic control (DIA-CTRL). 


\subsection{Serum Insulin Levels}

To facilitate identifying of the tested extracts or isolated active compound mechanism of hypoglycemia, the serum insulin levels were monitored prior to and 28 days post treatment. The serum insulin levels of the spray dried HS-sd has shown the highest dose dependant increase in serum insulin levels. Where various doses of HS-sd $(10,25$ and $50 \mathrm{mg} / \mathrm{kg}$ ) have shown ca. $5.0,7.1$ and 8.8 folds increase in serum insulin levels, respectively, 28 days post treatment, in correlation with vehicle treated diabetic mice (VEH) (Figure 6). While those of HS-r (10, 25 and $50 \mathrm{mg} / \mathrm{kg}$ ) have shown ca. 3.0, 4.4 and 5.8 folds increase in serum insulin levels, respectively, 28 days post treatment, in correlation with VEH (Figure 6). In comparison with VEH, HS-r and HS-sd, the lowest increase in serum insulin levels have shown by the isolated ICA which increased the serum insulin levels by 3.4, 4.1 and 5.3 folds, respectively (Figure 6).
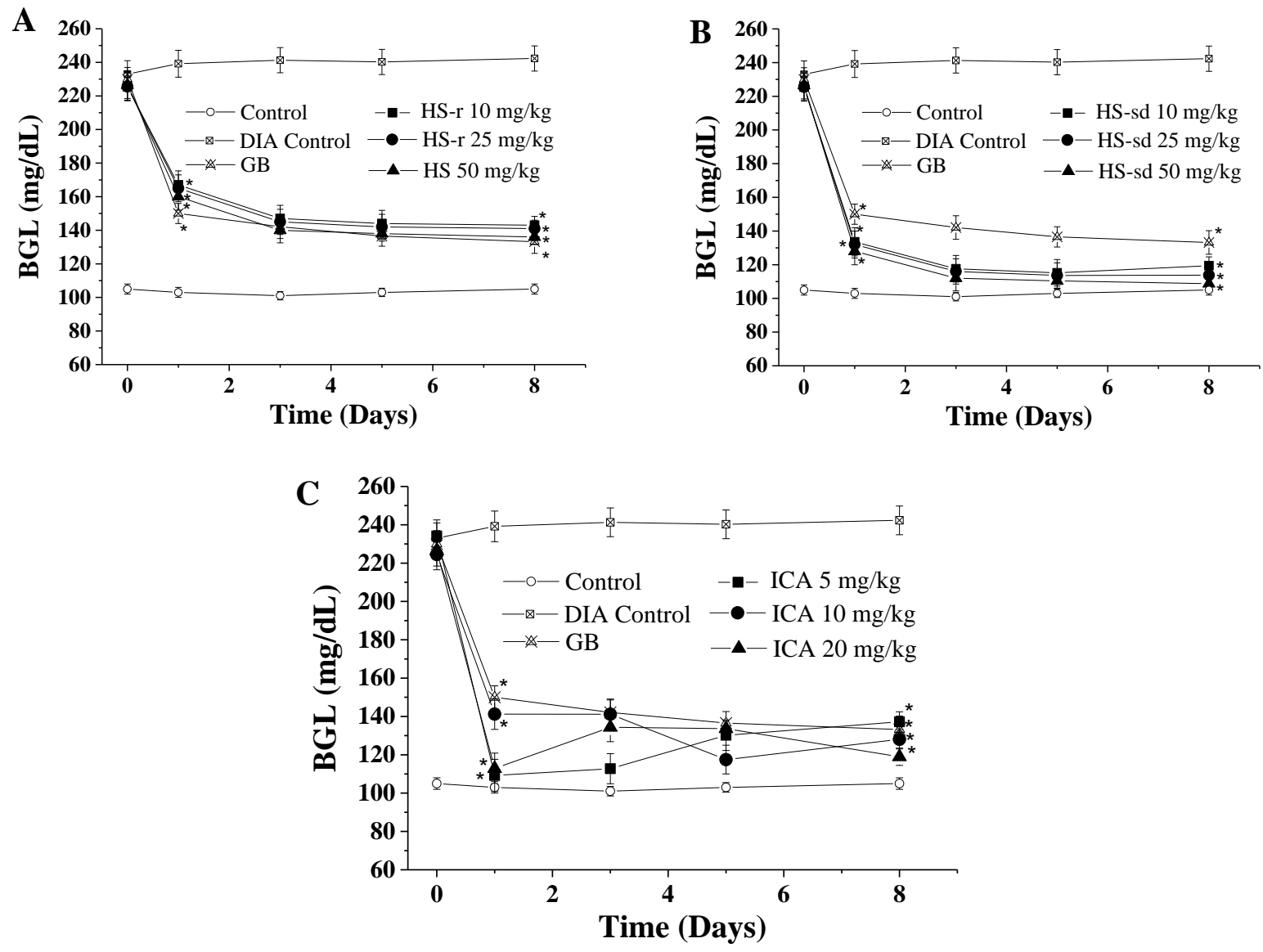

Figure 4. Subchronic hypoglycemic effect of the ((A) Rotary evaporated Honeysuckle aqueous extract (HSr); (B) ultrasound-assisted spray dried Honeysuckle aqueous extract (HS-sd); and (C) the isolated isochlorogenic acid (ICA) from HS-sd on BGL of experimental diabetic mice utilizing glibenclamide (GB) as positive control $(\mathrm{n}=7 /$ group). $\mathrm{CTRL}=$ normal non-diabetic control. $*$ means significant $(p<0.05)$ compared to vehicle treated diabetic control (DIA-CTRL).

\subsection{Body Weight Level as an Indicator of Management of DM}

The marked elevation in body weight (BW) levels is an indication of normalization of BGL [12]. Therefore, the average BW levels each of the treated animal groups were monitored subchronically for 8 days versus vehicle treated animals (VEH) (Figure 7). 
Subchronically, various doses of HS-r $(10,25$ and $50 \mathrm{mg} / \mathrm{kg})$ have increased the average BW at 8 days post-treatment by $45.4,48.8$ and $56.3 \%$, respectively, in correlation with VEH (Figure 7). Moreover, the same doses of the spray dried HS-sd $(10,25$ and $50 \mathrm{mg} / \mathrm{kg})$ have potentially increased the BW after 8 days post-treatment by 54.2, 62.5 and $65.4 \%$, respectively, in correlation with VEH (Figure 7). Furthermore, in correlation with VEH, various doses of ICA $(5,10$ and $20 \mathrm{mg} / \mathrm{kg}$ ) have increased the BW after 8 days post-treatment by 22.5, 30.4 and $44.6 \%$ (Figure 7). Interestingly, the results of HS-r, HS-sd and ICA were more prominent than that of the positive control, glibenclamide (GB) $5 \mathrm{mg} / \mathrm{kg}$ (Figure 7).

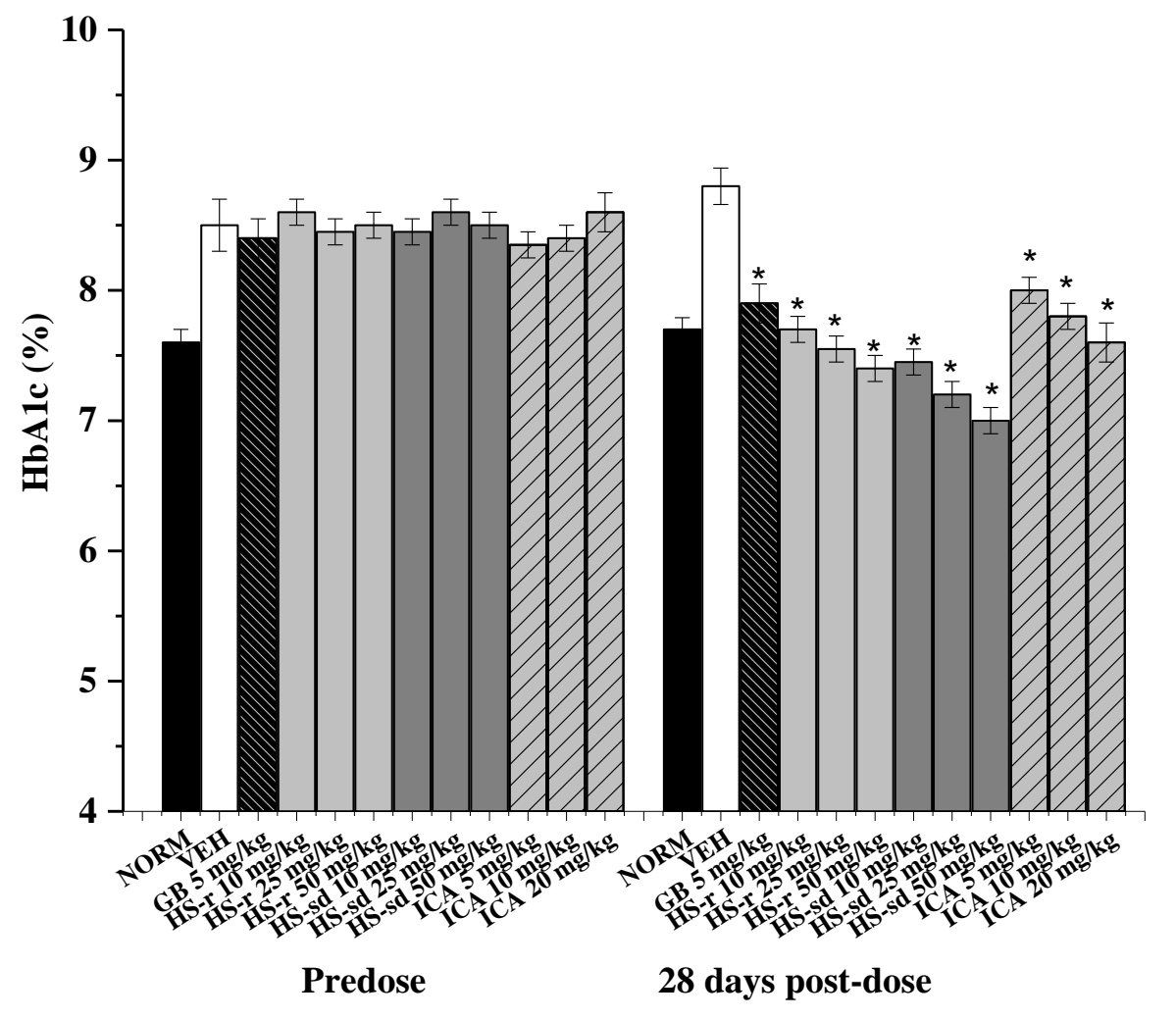

Figure 5. Effects of the rotary evaporated Honeysuckle aqueous extract (HS-r), ultrasound-assisted spray dried Honeysuckle aqueous extract (HS-sd) and isolated isochlorogenic acid (ICA) from HS-sd on $\mathrm{HbA1c}$ at pre-dose and 8 weeks post-dose utilizing glibenclamide (GB) as positive control $\left(\mathrm{n}=7 /\right.$ group). Values represent the mean $\pm \mathrm{SD}$. (NORM) normal non-diabetic untreated mice. ${ }^{*} p<0.05$ vs. diabetic vehicle control (VEH).

\subsection{L. etrusca extracts and DM Oxidative Stress}

The DM is marked by a significant increase of oxidative stress as indicated by the decrease in the innate antioxidant enzyme, catalase (CAT), and the re-elevation of CAT levels is an indication of good management of DM [13]. In this study, serum CAT levels decreased in the VEH group from 32.10 $\pm 0.14 \mathrm{kU} / \mathrm{L}$ (normal non-diabetic; NORM) to $19.50 \pm 0.10 \mathrm{kU} / \mathrm{L}$ (VEH), indicating of high oxidative stress in DM mice, before initiation of treatment (predose) (Figure 8).

Subchronically, various doses of HS-r $(10,25$ and $50 \mathrm{mg} / \mathrm{kg})$ have increased the CAT levels 8 days post-treatment by $28.1,37.7$ and $71.9 \%$, respectively, in correlation with VEH (Figure 8). Moreover, the comparable doses of the spray dried HS-sd $(10,25$ and $50 \mathrm{mg} / \mathrm{kg}$ ) have potentially increased the CAT levels after 8 days post-treatment by $31.1,55.8$ and $85.9 \%$, respectively, in correlation with VEH (Figure 8). Furthermore, in correlation with VEH, various doses of ICA $(5,10$ and $20 \mathrm{mg} / \mathrm{kg}$ ) have increased the CAT levels after 8 days post-treatment by 33.2, 43.2 and 72.9\% (Figure 
7). The results of HS-r, HS-sd and ICA highest doses were more prominent than that of the positive control, glibenclamide (GB) $5 \mathrm{mg} / \mathrm{kg}$ (Figure 8).

Thus, polyphenolic compounds have diverse phytotherapeutic activities and have been evidenced to be effective in the amelioration of serious disorders such as hypertension and diabetes [14]. RP-HPLC standardization of L. etrusca has shown it as a very rich source of polyphenolics. Moreover, a bio-guided fractionation and isolation study was applied in this study and the most active ingredient isolated from L. etrusca was found to be the polyphenolic, isochlorogenic acid (ICA).

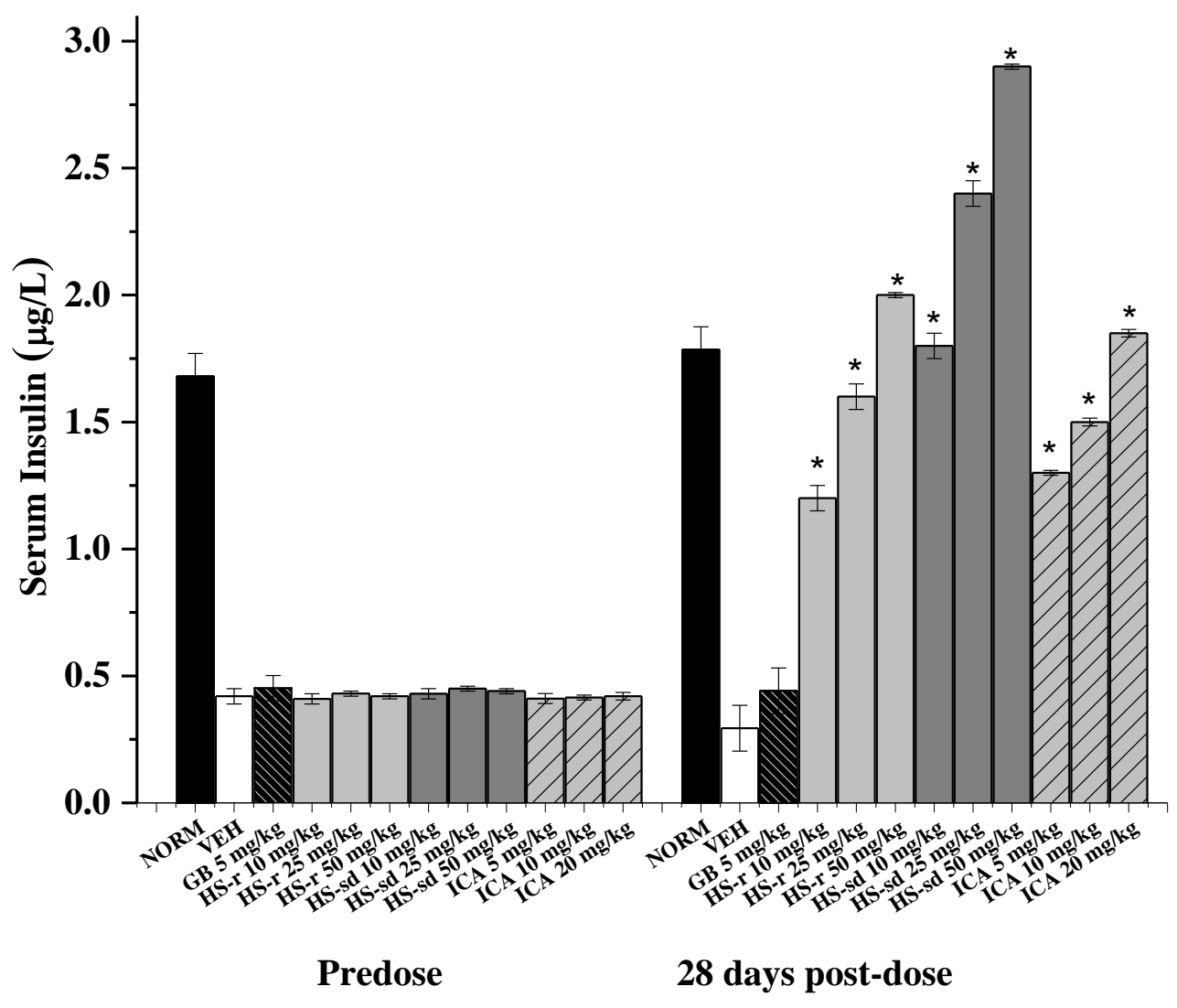

Figure 6. Effects the rotary evaporated Honeysuckle aqueous extract (HS-r), spray dried Honeysuckle aqueous extract (HS-sd) and isolated isochlorogenic acid (ICA) from HS-sd on serum insulin at pre-dose and 8 weeks post-dose utilizing metformin (MTF) as positive control (n=7/group). Values represent the mean $\pm \mathrm{SD}$. (NORM) normal non-diabetic untreated mice. ${ }^{*} p<0.05$ vs. diabetic vehicle control (VEH).

Currently, the conventionally dried honeysuckle (HS-r) has shown some antidiabetic potential. Nevertheless, in order to increase the hypoglycemic properties, ultrasound-assisted spray drying method was applied to aqueous honeysuckle extract (HS-sd). When compared to conventionally dried HS-r, the ultrasound-assisted spray dried HS-sd form has shown a significant improvement of processing time, yield, quality of constituents, and acute, subchronic and long-term antidiabetic activity.

In processing time, HS-sd has shown 4 fold decreases in drying time when compared to HS-r (Table 3), preserving time and might influence the quality of the constituents [15].

Furthermore, by comparing the yield after drying, HS-sd had ca. 20\% increase in yield when correlated to HS-r (Table 3), which improves the quantity of the extract being processed and have an economical benefit in increasing the processing yield [16]. 


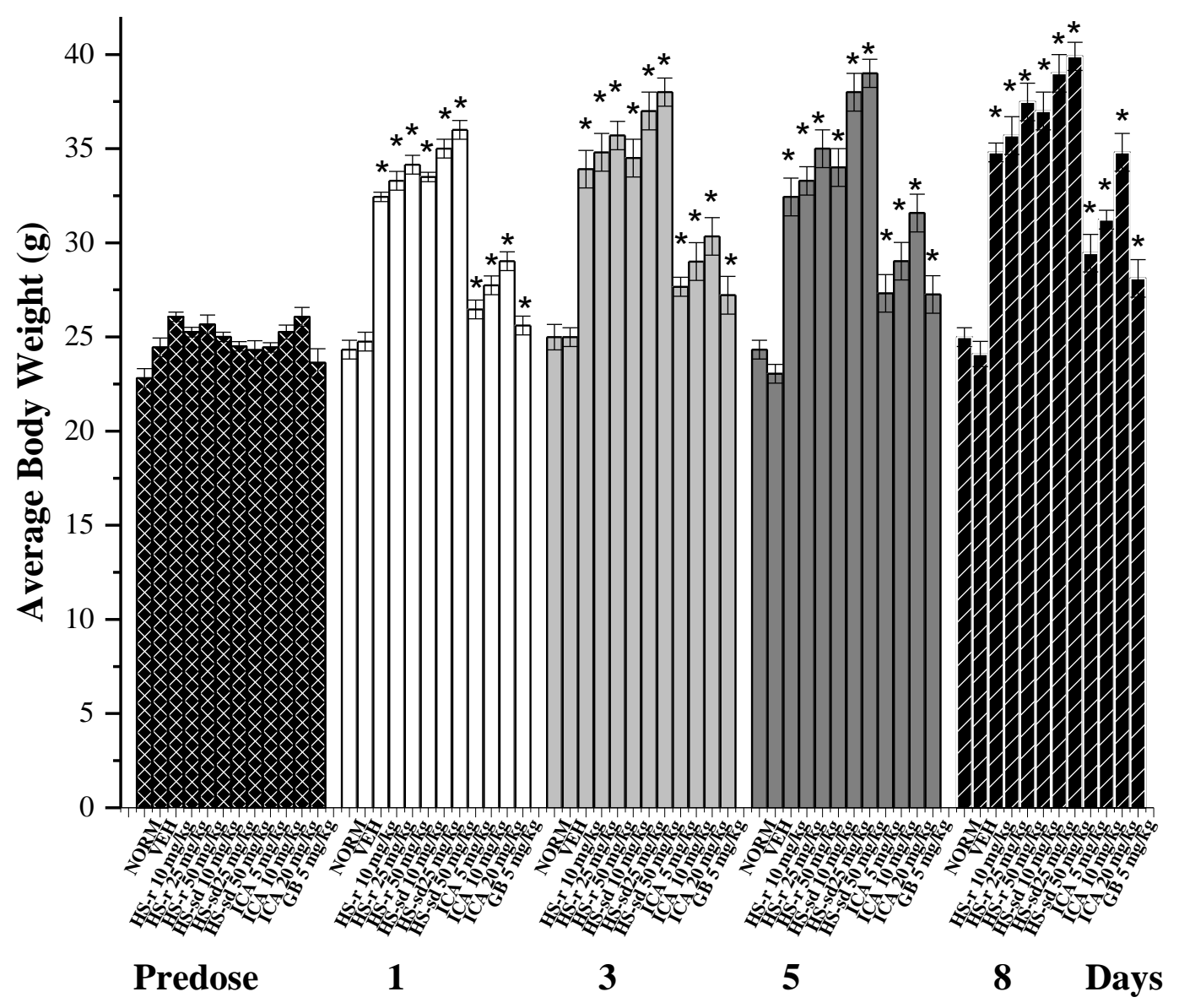

Figure 7. The effect the rotary evaporated Honeysuckle aqueous extract (HS-r), ultrasound-assisted spray dried Honeysuckle aqueous extract (HS-sd), isolated isochlorogenic acid (ICA) from HS-sd and glibenclamide (GB) $5 \mathrm{mg} / \mathrm{kg}$, as positive control, on body weights in alloxan-induced diabetic mice. NORM means normal non-diabetic mice. ${ }^{*} P \leq 0.05$ compared to vehicle treated group (VEH) (n=7 animals/group).

For the quality of the constituents, RP-HPLC standardization has found that there is a significant improvement in the most active constituent responsible for the antidiabetic activity, ICA. Where, HS-sd has ca. 19.9\% increase in ICA percentage when compared to HS-r (Figure 1), which might have strong influence on HS-sd efficacy and activity.

In order to investigate the antidiabetic properties of the tested compounds, an acute (6h), subchronic ( 8 days) and long-term (28 days) studies were assembled. In the acute studies, various doses of HS-r, HS-sd and ICA were utilized. The HS-sd has shown dose-dependent superiority in the antidiabetic activity over ICA and HS-r, giving the ultrasound-assisted spray drying an advantage in improving the L. etrusca antidiabetic efficacy.

For the subchronic experiments, HS-sd highest dose $(50 \mathrm{mg} / \mathrm{kg})$ has shown normalization of BGL and improving body weight when compared to vehicle treated diabetic animals (Figure 4B and 7). It was also more efficient than the highest doses of ICA and HS-r, indicating potential improvements in diabetes symptoms. 


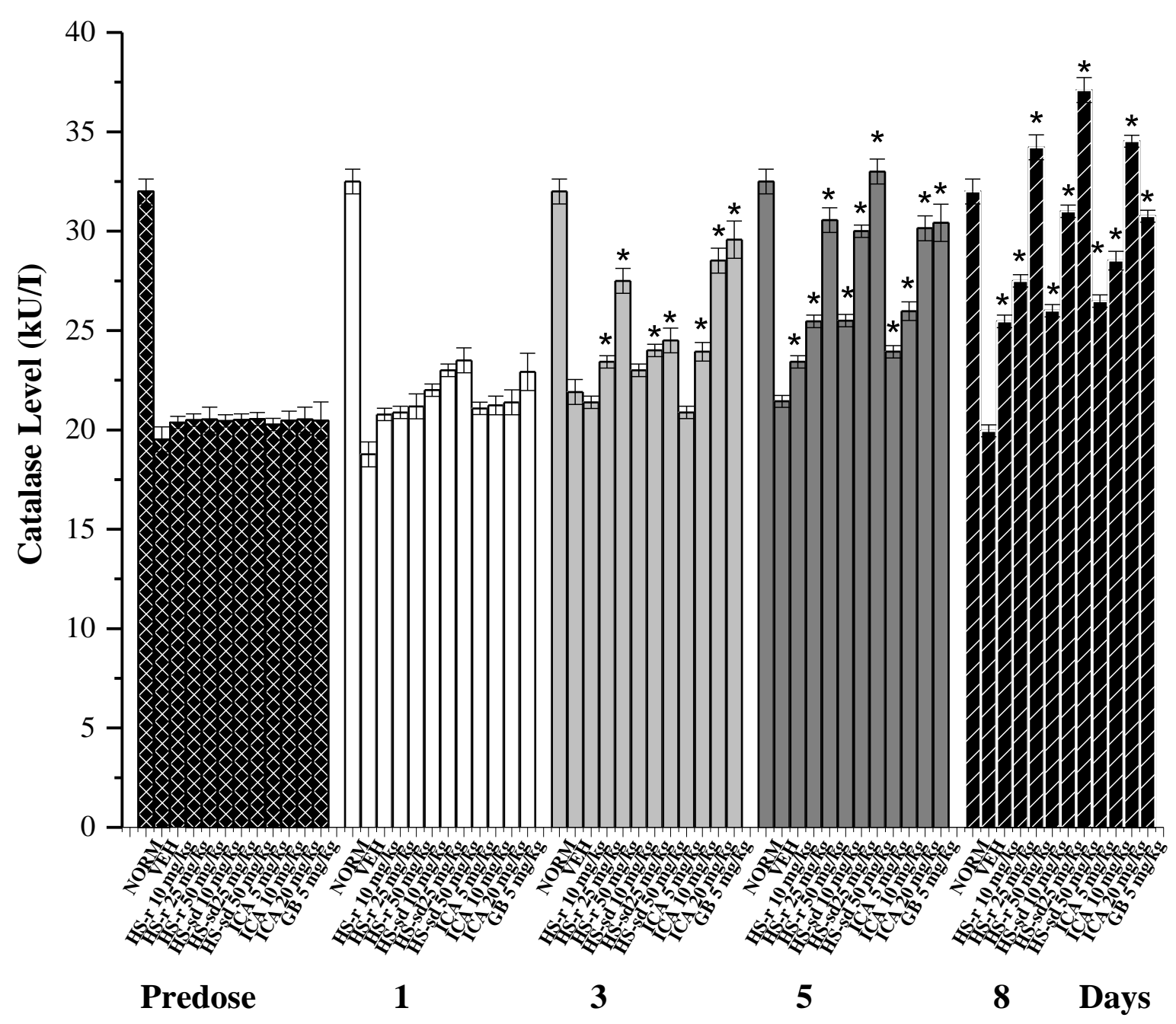

Figure 8. In vivo assessment of the antioxidant activity of the rotary evaporated Honeysuckle aqueous extract (HS-r), ultrasound-assisted spray dried Honeysuckle aqueous extract (HS-sd), isolated isochlorogenic acid (ICA) from HS-sd with glibenclamide (GB) $5 \mathrm{mg} / \mathrm{kg}$, as positive control; using CAT levels in serum of alloxan-induced diabetic mice. NORM means normal non-diabetic mice. ${ }^{*} P$ $\leq 0.05$ compared to vehicle treated group (VEH) ( $\mathrm{n}=7$ animals/group).

Furthermore, the long-term management of diabetes has shown that HS-sd at its highest dose $(50 \mathrm{mg} / \mathrm{kg}$ ) has shown normalization of $\mathrm{HbA1c}$ levels when compared to vehicle treated diabetic animals (Figure 5), and more efficient than the highest doses of HS-r and ICA. These findings might pave the way for HS-sd to be a potential future phytotherapy to ameliorate diabetes.

To facilitate identifying the antidiabetic mechanism of the tested compounds, serum-insulin levels and monitoring of the oxidative stress, using serum CAT-levels, have been utilized.

For serum-insulin levels, the HS-sd has shown dose-dependent superiority in the insulin secretagogue potentials. Yet, ICA has shown also powerful insulin secretagogue potential. Thus, the insulinsecretagogue potential may be attributed to ICA and other polyphenolics present in L. etrusca.

Nevertheless, serum CAT-levels have increased significantly and dose dependently with HS-sd, indicating the decrease of diabetic-induced oxidative stress and good amelioration of diabetic symptoms.

In conclusion, L. etrusca has shown to be good source of polyphenolics and has long-term potentials to control diabetes symptoms, mediated by decreasing diabetes oxidative stress and increasing 
insulin secretagogue potentials and its efficacy might be improved by ultrasound-assisted spray drying. The ultrasound-assisted spray drying of L. etrusca has shown improvement of processing time, yield, quality of constituents, and acute, subchronic and long-term antidiabetic activity over the conventional method. Thus, it is recommended to take ultrasound-assisted spray dried L. etrusca antidiabetic potentials into consideration when clinically developing novel antidiabetic dietary supplements in the future.

\section{ORCID}

Karim M. Raafat: 0000-0001-5907-6956

Wael Samy: 0000-0001-6082-8705

\section{References}

[1] W. Aidi Wannes and B. Marzouk (2016). Research progress of Tunisian medicinal plants used for acute diabetes, J. Ac. Dis. 5, 357-363.

[2] B. Güler, E. Manav and E. Uğurlu (2015). Medicinal plants used by traditional healers in Bozüyük (Bilecik-Turkey), J. Ethnopharmcol. 173, 39-47.

[3] S. Güneş, A. Savran, M.Y. Paksoy, M. Koşar and U. Çakılcıoğlu (2017). Ethnopharmacological survey of medicinal plants in Karaisalı and its surrounding (Adana-Turkey), J. Herb. Med. 8, 68-75.

[4] W. Wojnar, I. Kaczmarczyk-Sedlak and M. Zych (2017). Diosmin ameliorates the effects of oxidative stress in lenses of streptozotocin-induced type 1 diabetic rats, Pharmacol. Rep. 69, 995-1000.

[5] L. Gallo, M.V. Ramírez-Rigo, J. Piña and V. Bucalá (2015). A comparative study of spray-dried medicinal plant aqueous extracts. Drying performance and product quality, Chem. Eng. Res. and Des. 104, 681-694.

[6] A.O. Elzoghby, W.M. Samy and N.A. Elgindy (2013). Novel spray-dried genipin-crosslinked casein nanoparticles for prolonged release of alfuzosin hydrochloride, Pharm. Res. 30, 512-22.

[7] W. Guo, L. Wang, Y. Gao, B. Zhao, D. Wang, W. Duan and Z. Yu (2015). Isolation of isochlorogenic acid isomers in flower buds of Lonicera japonica by high-speed counter-current chromatography and preparative high performance liquid chromatography, J.Chrom. B 981, 27-32.

[8] P.V.A. Babu, D. Liu and E.R. Gilbert (2013). Recent advances in understanding the anti-diabetic actions of dietary flavonoids, J. Nut. Biochem. 24, 1777-1789.

[9] B. Sarmento, A. Ribeiro, F. Veiga and D. Ferreira (2006). Development and validation of a rapid reversed-phase HPLC method for the determination of insulin from nanoparticulate systems, Biomed. Chrom. 20, 898-903.

[10] K. Raafat, N. El-Darra, F.A. Saleh, H.N. Rajha, R.G. Maroun and N. Louka (2017). Infrared-assisted extraction and HPLC-analysis of Prunus armeniaca L. pomace and detoxified-kernel and their antidiabetic effects, Phytochem. Anal. 1-12. doi: 10.1002/pca.2723.

[11] W.G. Yasmineh, T.P. Kaur, B.R. Blazar and A. Theologides (1995). Serum catalase as marker of graftvs-host disease in allogeneic bone marrow transplant recipients: Pilot study, Clin. Chem. 41, 1574-80.

[12] T. Bakirel, U. Bakirel, O.U. Keles, S.G. Ulgen and H. Yardibi (2008). In vivo assessment of antidiabetic and antioxidant activities of rosemary (Rosmarinus officinalis) in alloxan-diabetic rabbits, $J$. Ethnopharmacol. 116, 64-73.

[13] A. Elosta, T. Ghous and N. Ahmed (2012). Natural products as anti-glycation agents: Possible therapeutic potential for diabetic complications, Curr. Diab. Rev. 8, 92-108.

[14] I.C. Arts and P.C. Hollman (2005). Polyphenols and disease risk in epidemiologic studies, Am. J. Clin. Nutr. 81, 317S-325S.

[15] I. Tontul and A. Topuz (2017). Spray-drying of fruit and vegetable juices: Effect of drying conditions on the product yield and physical properties, Tren. Food Sci. \& Tech. 63, 91-102.

[16] D. Shofinita, S. Feng and T.A.G. Langrish (2015). Comparing yields from the extraction of different citrus peels and spray drying of the extracts, Adv. Powd. Tech. 26, 1633-1638.

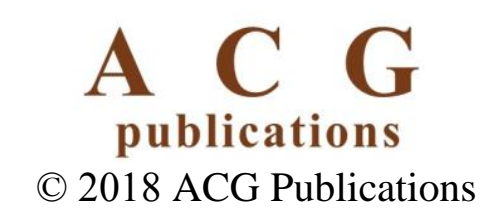

